\title{
Problems of Logical-mathematical Modeling in the Course of Cribwork Quay Design: Innovative Methods of Civil Engineering
}

\author{
Igor Pryadko, ${ }^{1, *}$ \\ ${ }^{1}$ Moscow State University of Civil Engineering, Yaroslavskoe shosse, 26, Moscow, 129337, Russia
}

\begin{abstract}
In the article, the author analyzes the innovative methods, employed by the Russian hydraulic engineer Nikolai Mikhailovich Gersevanov in the course of the stability analysisperformed in respect of cribwork quays. The author addresses one of the little known works, written by this Russian architect of industrial buildings. The work in question covers the application of logic algebra formulas to the substantiation of the stability of foundations of quays and port structures; it is entitled "The Application of Mathematical Logic to the Analysis of Structures". N.M. Gersevanov employs his method of logical-mathematical substantiation of stability of cribwork quays as an example in the second part of his research. The author also analyzes the features of construction of crib piers, the forces that they are exposed to, and any possible reasons for the destruction of cribwork quays. In this article, the problem of design of cribwork quays is tied to the problem of construction performed in the context of natural (hydrologic and tectonic) calamities, such as earthquakes, tsunamis, floods, and landslides. City and port management amid natural calamities represents an innovative challenge to be met by contemporary architects. The analysis of conditional propositions, employed in the work, written by N.M. Gersevanov, has proven his paper's novelty. The author of this article believes that antecedent and consequent are connected by the symbol of relevant (or nomological) implicationin hispropositions.
\end{abstract}

\section{Logic as the Basis for Innovative Projects in Technology and Urban Planning}

Any construction projects, implemented in severe environments, that make the final result impossible to predict, force their developers, including civil engineers and architects, to employ versatile innovative methods. [1] According to the author, innovation consists in the employment of mathematical logic and its methods. They make it possible to simulate decision making processes and substantiate the stability of civil and industrial buildings to be built. Designers and civil engineers face fairly complicated innovative challenges consisting in the construction of new facilities. In the $21^{\text {st }}$ century, engineering challenges

${ }^{*}$ Corresponding author: priadcko.igor2011@yandex.ru 
are aggravated by the environmental requirements applicable to construction projects. More attention is drawn to problems of earthquake-proof construction and development of construction projects in the areas exposed to potential hydrological, climatic, tectonic, maninduced and machinery-related emergencies. Environmental engineers and urban designers systematize the reasons for the collapse of architectural facilities exposed to these emergencies. Suffice to say that port facilities, constructed in wedge-shaped bays, can be washed away by a tsunami, which can be up to 50 meters high; therefore, it is particularly important that the foundations of embankments, bridge piers, or nearby buildings were resistant to kinking, overturning, etc.It's highly important to remember that one hundred out of a thousand tsunamis have disastrous consequences. Tsunamis, caused by waterquakes and near-shore earthquakes, are frequent in the Pacific region. In 1933, a strongest tsunami flooded the shoreline of Japan. In 1952, giant ocean waves damaged severalmaritime towns in the Kamchatka peninsula. Tsunamis are particularly frequent in the area of the Kamchatka-Kurilsk trench. Up to $28 \%$ of the regions in the present-day Russia are considered asquake-prone. It should be pointed out that the majority of all quakes represent seaquakes, rather than earthquakes, and seaquakes are less intensive.

It is worth remembering that there exists an interrelation between different types of natural disasters. Each tropical cyclone causes a flood; earthquakes cause tsunamis; earthquakes in mountainous areas cause industrial emergencies, fires, gas explosions, and dam failures. Many ports are constructed in the areas exposed to tsunamis. That's why the states that have shorelines, exposed to tsunamis, including the USA, Japan, the Russian Federation, maintain tsunami alarm services, responsible for theirforecasting. The design of quays and port structures, resistant to destruction, caused by natural disasters, is also a significant challenge to be met by the engineers in these countries. The problem of cribwork quays, exposed to kinking, shifting, and overturning, caused by natural reasons, and also to thrust, caused by the backfill soil, that impacts the cribwork, was solved by Mikhail Nikolayevich Gersevanov, an outstanding Russian engineer and designer of several quays in the south of Russia (Nikolayev, Odesa, Kerch). The ideas and methodological principles, developed by this hydraulic engineer were developed by his son, Nikolai Mikhailovich Gersevanov, who lived and worked in the days of the USSR, in the 20ies and 30 ies of the $20^{\text {th }}$ century. This time period is famous for the so-called Soviet five-year industrial plans. It was the time when the flagships of the Russian industry were designed and constructed, when next-to-impossible urban planning and transport projects were implemented (including TurkSib, or the railroad connecting Siberia and Central Asia; the Moscow metro, the Novokuznetsk smelter, the Chelyabinsk tractor factory, and the metal smelter in Zaporizhia. Nikolai Mikhailovich Gersevanov invested his talent and effort into some of these undertakings (please refer to [2] for details).

This Russian engineer came into the spotlight as a hydraulic engineer. Unlike his father, Gersevanov, Jr. developed his projects for difficult to access terrains which could hardly accommodate any quays. Before we analyze Nikolai Gersevanov's approaches to the construction of port facilities and quays, we will address the language of Boolean algebra, developed by Louis Couturat, an outstanding French mathematician. Nikolai Gersevanov employed this language in his logic-based research. His research projects perfectly fit the context of the 20 ies and 30 ies of the $20^{\text {th }}$ century. These decades were exceptionally prolific for the Russian industry, Russian architecture and urban planning. This period is widely covered by the historians focused on the Russian schools of architecture [4]

The research project, discussed in this article, is based on the conclusions made by the logicians, specialists in applied mathematics, and engineers responsible for the development of methods ofquay/port structure construction. The author believes that the works written by the historians of mathematics and logic, namely, by B.V. Biryukov, V.I. Levin, I.S. Verstina [5], Z.A. Kuzicheva [6], A.D. Ishkov [7], etc. are of particular 
importance to this research and article. Indeed, B.V. Biryukov and Z.A. Kuzicheva attempted to compare Gersevanov's engineering solutions to those made by other researchers. As a result, we can create a group of researchers, specializing in the same field of knowledge. They are Paul Ehrenfest, Nikolai Gersevanov, and Viktor Shestakov. [8] This way we can track the development of applied logic from the very first assumptions, made by Paul Ehrenfest, to the automata theory and the application of Boolean algebra to the synthesis/analysis of switching circuits. These researchers determined the influence ofthe first cases of application of mathematical logic on applied research projects, namely, the influence, produced on the Shestakov's school of thought by the developments that date back to the 20 ies and 30 ies of the $20^{\text {th }}$ century. The research literature draws a lot of attention to the application of logic in cybernetics and information science. As for the former, the researchers draw attention to the method of modeling in technology. Numerous authors (including Biryukov, Geller, etc.) [9] considerthe logical validation of modeling in technology. The value of Gersevanov's works is appreciated both by the historians of logic andtheorists of urban planning who believe that his ideas are particularly valuable for structural mechanics, soil mechanics and loose material mechanics. The development stages of the civil engineering theory are tracked in the book "Fundamentals of Urban Planning" written by Lazarev and Shein, in the Gersevanov's biography, written by Boutodlayev, and in several other sources.

The author has also takenadvantage of several open access sources ofinformation, including the ecological monitoring findingsrelated to the emergencies that forced civil engineers to improve the sustainability of structures in quake-prone areas and in other areas exposed to regular floods/other calamities. The materials, analyzed by the author, include several quays and port structures, destroyed by natural disasters and selected by Gersevanov to illustrate his conclusions.

\section{Materials and Methods}

Let's identify the methods, employed in this research, and consider the implications for the use of logic in urban planning and architecture. In this work, the author employs the methods of formal logic and the theory of reasoning to substantiate the stability of foundations of hydraulic structures. According to this methodology, propositions are presented as formulas in the language of prepositional logic in order to assess the validity of argumentation. The author employs the analog method to compare the conclusions of the Russian logicians to those derived by their foreign colleagues andto compare the presentday symbols of prepositional logic to the formalized language, used by Gersevanov. The method of tables or transformations isapplied to check the accuracy or validity of the reasoning patterns, employed to substantiate the stability of structures. Propositions, employed in the process of reasoning, are replaced by variables in the language of logic. Evidently, the Soviet engineer welcomed the fact that propositions, written in the language of alphabetical symbols, could be manipulated in accordance with the rules, similar to those of elementary algebra.

The author employs contemporary symbols of the logic of propositional calculus, which is slightly different from the obsolete symbols used by the Russian engineer. In our methodology section we will make an attempt to compare these two systems of symbols:

$\neg$ stands fornegation (instead, Gersevanov used a stroke over variables),

$\&$-stands forconjunction (this operation is described by Gersevanov as omission of any sign or a bullet),

$\supset$ - stands forimplication (while Gersevanov used the angle sign), 
$\vee-$ stands for disjunction (in Gersevanov's Boolean logic, this operation is described as $\mathrm{a} \ll+\gg)$

三stands forequivalency;

[,], (,) stand for parentheses.

$a, b, c$, etc. are the propositional variables that replace elementary propositions that make part of complex propositions.

The term that reads as "a propositional variable" initially appeared in the works written by George Bull and Alfred de Morgan. The systems, developed by these two mathematicians, are considered to be the first systems of Boolean algebra; therefore, this notion, derived from the English word "proposition", is widely spread. [10]

The author employs meta-variables $\mathfrak{I}, \mathfrak{R}, \aleph$ to denote correctly compiled formulas (the definition of a correctly compiled formula is provided in [11]).

If $\mathfrak{I}, \mathfrak{R}, \mathfrak{\aleph}$ represent correctly compiled formulas, then the propositions $\neg \mathfrak{I},(\mathfrak{R} \& \mathfrak{\aleph}),(\mathfrak{R} \vee \mathfrak{N}),(\mathfrak{I} \supset \mathfrak{R}),(\mathfrak{I} \equiv \mathfrak{R})$ represent correct formulas. We also indicate that, according to Gersevanov, "<" meant a material implication, and this symbolwas introduced to denote a conventional connection between propositions. Gersevanov interpreted this symbol as a substantive connection between argument and consequence. For example, $A<B$ means thatBis the necessary condition for $A, A$ is the sufficient condition for $B$. If $A<B$ and $B<A$, then $A$ and $B$ maintain the relation of equivalency (a civil engineer puts an equal mark here). We can describe these relations in the following way: $[(\mathfrak{J} \supset \mathfrak{R}) \&(\mathfrak{R} \supset \mathfrak{I})] \supset(\mathfrak{I} \equiv \mathfrak{R})$.

Further, Gersevanov introducedthe notions of logical zero and logical one. $X$ will be equal to logical zero, if and only if $0<X$ и $X<0$. $\mathrm{X}$ is equal to logical one, if and only if $X>1$ and $X<1$. According to N.I. Styazhkin, the availability (1) and absence (0) of some quality were used by I. Lambert (1728-1777), a famous German logician. Later, this system was employed by A. de Morgan and G. Bull. [12]

The author employs the method of retrospective analysis of sources, the biographical method and the comparative historical method, when he addresses the history of mathematical logic, the Russian schools of mathematical logic in the $20^{\text {th }}$ century, and in the course of his research into particular periodsof the history of the Russian school of soil mechanics.

\section{Results}

The subject of research, covered by this article, represents a cribwork quay; its drawing is provided in N.M. Gersevanov's work entitled "The Application of Mathematical Logic in the Analysis of Structures". Let us clarify several definitions used by the author of this article. Initially, a crib meant a timber blocking, submerged into soil mixed with clay and cobblestone (or other bulky material). A crib serves as the foundation for dams and, more rarely, for moles and bridge piers. However, more frequently cribs serve as foundations for quays. Cribwork is widely spread in Northern areas, such as Scandinavia, Canada, and Russia. Presently, concrete cribwork structuresare also widely spread. Their popularity is mainly driven by their cost effectiveness and ability to prevent landslides and other destructions. The strengths of cribwork quays include their inexpensiveness (applying both to construction materials and construction time). The consumption of cobblestone is lower in case of cribwork quays than in case of quays built on dumped rock foundations. Nonetheless, cribwork quays have their weaknesses to be discussed further in this work.

Gersevanov was willing to identify preventive geotechnical measures, that couldavert any destruction caused by natural geodynamic processes, such as subsidence, floods, soil extrusion, etc. Cribwork quays and port structures are often destroyed in case of their 
exposure to varied natural calamities, including earthquakes, volcanic eruptions, and tsunamis. In the course of history, port structures and quays of maritime towns were regularly exposed to destructive earthquakes. In 1755, Lisbon was destroyed by an earthquake. Notably, its consequences were aggravated by the flood that followed the aftershocks. In 1960, Agadir, a Moroccan port, was the hypocenter of an earthquake, while in the February of 1970, the hypocenter of a devastative earthquake was located in California.

The monitoring of emergencies, that have occurred along the coastlines in 2018 has generated a sufficient collection of data to be generalized. Indeed, as a result of an earthquake in Taiwan (having the magnitude of 6.4), some buildings and structures, located in the coastline area, were fouled. According to the information, published by the local media, the hypocenter of this earthquake was located somewhere along the Eastern coast; therefore, seismic waves affected the shelf zone and the dry land. Another earthquake was particularly strong in the city of Hualien. The structures, located in close proximity to the shoreline, leant; some of them were gravely damaged. For example, the inclination angle of the Marshal hotel reached 30 degrees, and therefore, any guests, who remained inside, had to be urgently evacuated from the hotel building. [13] The author has no idea whether there were any cribwork quays built along the coastline of Hualien. Meanwhile, there are many cribwork quays in the cities and towns of Siberia and Far East, including Surgut, Vladivostok, Komsomolsk-on-Amur. Therefore, the analysis of their stability, performed by N.M. Gersevanov in 1923, is valuable today. The formula, developed by N.M. Gersevanov in the terms of logical algebra, equips present-day architects with e methods of design of quays, port structures, and highways to be built in littoral areas.

Gersevanov's deliberations originate from the analysis of the forces, that the cribwork is exposed to, and that cause the deformation of quays and makesubstructures shift in the longer run. According to Gersevanov, "In order to make sure that the quay is stable, we need to make sure that it's resistant to any possible types of destructions, that it is resistant to shear, soil extrusion, etc." [14] However, the types of destructions, mentioned by N.M.Gersevanov in his work, are typical not only for cribwork quays, but also for massive quays, as well as the quays and port structures resting on the foundations made of built-inplace and slag-cement piles, while Gersevanov's mission is to narrow down the problem to be solved by the designers of cribwork quays. Therefore, a specific section of this work covers the design of this type of quays.

The author of the first logic-related article, written in the Soviet era, limits his research to the deformations caused by the impact produced on the cribwork by soil. Most frequently, "the cribwork that has the shape of a rectangle in its cross section, reshapes into a parallelogram, and this deformation is so significant that the cobblestone, representing its nucleus, shifts towards the cribwork inclination side" (see Fig. 1). In some cases, the shifts are accelerated by tectonic tremors in the earthquake zones.

Any designs of this type require that shifting is prevented by thecrib width. As the layers, resting on one another, are exposed to shifting, pressure $t$ depends on the value of $f$, the cobblework friction coefficient. Besides, the value of $t$ is in direct proportion to the perunit weight of cobblework $\square \square \square$ and to the width of crib $r$. Therefore, we can derive the following formula:

$$
t=f \Delta r
$$

where $\mathrm{t}$ is the pressure that the cribwork is exposed to, $f$ isthe cobblework friction coefficient, is the per-unit weight of the cobblework, and $r$ is the width of the cribwork.

Gersevanov considers the following conditional proposition that needs to be substantiated by any architect in charge of the design of a cribwork quay:

$A<B$, where $A$ is the proposition that reads as "this cribwork quay is stable" 


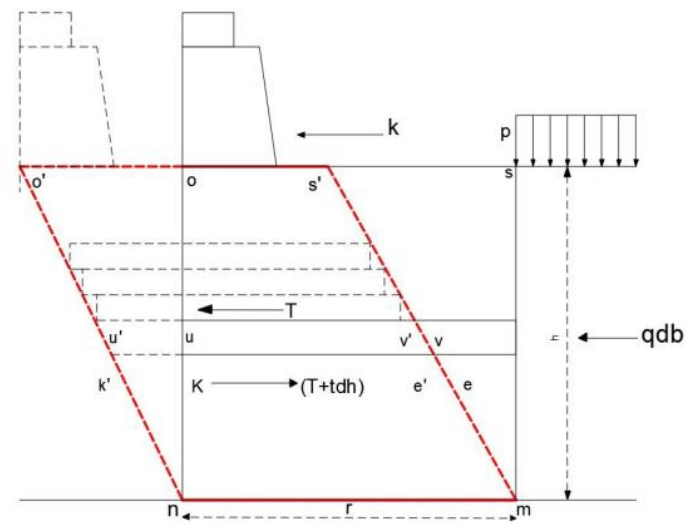

Fig. 1. Deformation of a cribwork quay.

The problem, formulated by Gersevanov, is to identify the width of themnos (see Fig. 1) cribwork to prevent its destruction caused by the shift. The problem, raised by the hydraulic engineer, is to be solved not only through the employment of soil/bulky material mechanics, but also through the employment of Boolean logic. Gersevanov states that "this problem will hardly be solved if any elastic deformation is considered using methods of structural mechanics," [14] It is necessary to excavate the earth and fill the klvu (see Fig. 1) crib with a layer of cobbles to make a cribwork quay. The soil pressure will spread between the cobblework and the timber frame. The value of the former is identified through $r d h$, while the value of the latter is identified through $e d h$. These two relations serve as the antecedent for the implication $A<B$, derived by the Russian hydraulic engineer. In the next section, we will consider the nature of this implication and touch upon its debating points.

\section{Debates about Conventional Propositions in N.M. Gersevanov's Logical Algebra}

According to G.W. Leibniz, methods, employed to solve theoretical and applied problems, are not less important than discoveries made in various areas of research. Therefore, in this section we will analyze the instruments of formal logic, employed by this outstanding Russian hydraulic engineer. The issue of motivation that serves as the basis for any human activity causes most numerous debates. Our conclusions, made in this respect, are highly probabilistic. Therefore, we place the discussion of this issue into the "Debates" section of our article.

Nonetheless, we will do our best to identify the reasons why Gersevanov employed symbols to present the research information related to the development of port structures. We believe that his motives are similar to those that make all engineers and urban planners use logical algebra. Firstly, logical algebra is more compact that any natural language. Secondly, in the course of analysis of abstract symbols, the findings of the combinatorial analysis of lexico-grammatical classes presented in the form of symbols (representing notions and regularities of classical mechanics) turnclear. Any symbolic representation demonstrates connections between thoughts; therefore, arguments turn easier to identify. The third reason for the employment of symbols of logical algebra reads as follows: formalized inscriptions are close to algorithmic languages, and the lattercan make it possible to computerize the process of reasoning and to simplify its programming. 
However, Gersevanov didn't go that far, as he lived in the days when cybernetics and the automata theory were still "in swaddling clothes". However here we can speak about an attempt to rationalize the process of structural design.

Whenever we work with propositions, we can group the reasoning results into truth diagrams, and this is another reason for the use of the language of mathematical logic in design-related discussions. [15] That's why Z.A. Kuzicheva, a contemporary logician, considers symbolic logic an artificial language and an example of mathematical calculation, thus, stressing its interim status. It serves as the crossing point betweeninformation science, technological modeling, mathematics, and theoretical sciences that determine methods of applied research.

\section{Conclusions}

In this paper, the author has attempted to analyze an excerpt from the first articleon the use of structural mechanics in the course of substantiating the stability of hydraulic structures. Although in the ancient times logic was declared the propaedeutics of all sciences and the methodological basis of any human activities, only in the $20^{\text {th }}$ century this idea developed into something more specific. The computerization of various areas of human activities was preceded by the use of formal logic in power/civil engineering. The author of this article is sure that Gersevanov's research into problems of logical algebra must serve as the example for contemporary engineers and architects.

However, neither logical experiment, conducted by Gersevanov, has drawn any attention of our contemporaries. Back in the 60ies and 70ies of the 20 ht century, the synthesis of logic and technology was implemented in the theory of automata and calculators. The research into problems of logic has entered a new stage of development. However, many authors believe that the history of Russian cybernetics started in the days of the Lyapunov's seminar, and they are very reticent about its prehistory, or the works written by Gersevanov and Shestakov. [16] However, the discussion of any further stages in the development of theories of mathematical logic falls beyond the subject of this article.

We would like to address another issue that proves the importance of research into the first attempts to introduce logic into engineering analysis. We believe that the article, written by Gersevanov, unmasked the "conspiracy of silence" on mathematical logic, which hadbeendeclared incompatible with dialectical materialism. We find is next to impossible to disagree with the expert's opinion, as professor B.V. Biryukov said: "The logical thought was in the mandatory manner opposed to the dialectical logic, the school that was nothing but dialectical materialism or Marxist Hegelianism." [17]

Thanks to the studies performed by N.M. Gersevanov and V.I. Shestakov, an electrical engineer, whose biography and contribution has been extensively covered in the research literature, mathematical logic was successfully applied to numerous research projects, including those in the field of civil engineering and architecture. Now it is clear that the study of Gersevanov's legacy, including his application of mathematics and mathematical logic in civil engineering, can throw light on the pace of any applied research performed in our country in the $20^{\text {th }}$ century, and it can make it possible to track the development of logicin the 30 ies and 40 ies of the $20^{\text {th }}$ century.

\section{References}

1. A.D. Ishkov, M.Y. Mishlanova, K.P. Grabovyi, Intl J. of Appl. Engineering

Research,11, 3 (2016) 
2. N. M. Budtolayev, M.N. Gersevanov, an outstanding theorist of hydraulic engineering in ports: an essay on life and work. On the one hundred and twentieth anniversary (Moscow, 1950)

3. L. Couturat, Logic algebra (Moscow, Librokom, 2012)

4. A.G. Lazarev, S.G. Sheina, Fundamentals of urban planning (Rostov-on-Don, Feniks, 2004)

5. B.V. Biryukov, I.S. Verstin, V.I. Levin, Research in Logic, 14 (2007)

6. B. Biryukov, Z. Kuzicheva, Contemporary logic: problems of theory, history and application in research (St. Petersburg University, 2008)

7. I. Pryadko, A. Ishkov, Procedia Engineering, 165(2016)

8. B. Biryukov, V. Shakhov, A. Karpenko, editor.Research in logic, 14 (Moscow: Nauka, 2007).

9. B.V. Biryukov, E.S. Geller, Cybernetics in humanities (Moscow, Nauka, 1973)

10. B.V. Biryukov, V.N. Trostnikov, The heat of cold figures and the pathos of dispassionate logic (Moscow, Editorial URSS, 2004)

11. G.A. Levin, V.I. Barton, Logic (BGU, 1974)

12. N.I. Styazhkin, Philosophical sciences, 3 (1958)

13. The number of the earthquake victims went up overnight into February 7, Moskovsky Komsomolets (AssociatedPress, February 08, 2018)

14. N.M., Gersevanov The application of mathematical logic to the analysis of structures, 1 (Moscow, Stroyvoyenmorizdat, 1948)

15. Z.A. Kuzicheva, Issues of cybernetics. Cybernetics and mathematical logic in the historical and methodological aspect (Moscow, Academy of Sciences of the USSR, 1984)

16. M.G. Gaaze-Rapoport, Philosophical research, 4 (1993)

17. B.V. Biryukov, Proceedings of the International Slavonic University, 4, (Moscow, 1998) 